\title{
SOSIALISASI DAN PELATIHAN MEMANFAATKAN LAHAN PEKARANGAN RUMAH MENJADI KAWASAN PANGAN LESTARI (KPL) UNTUK MENINGKATKAN KESEJAHTERAAN MASYARAKAT
}

\author{
Binti Mualifatul Rosydah ${ }^{1 *}$, Rini Indarti ${ }^{2}$, M. Basuki Rahmat, Isa Rachman ${ }^{3}$, Purwidi Asri ${ }^{3}$, Mey Rohma \\ Dhani $^{1}$, Achmad Ainnurzein ${ }^{2}$, Lutfi Wicaksono ${ }^{1}$, Bella Naziel Iqmalia ${ }^{1}$ \\ ${ }^{1}$ Teknik Keselamatan dan Kesehatan Kerja, Politeknik Perkapalan Negeri Surabaya \\ ${ }^{2}$ Teknik Kelistrikan Kapal, Politeknik Perkapalan Negeri Surabaya \\ ${ }^{3}$ Teknik Otomasi, Politeknik Perkapalan Negeri Surabaya \\ Jalan Teknik Kimia, ITS \\ email: binti.mualifatul@gmail.com
}

diterima tanggal : 12 Juli 2018 disetujui tanggal : 20 November 2018

\begin{abstract}
Abstrak
Konsep kawasan pangan lestari adalah konsep pemanfaatan lahan pekarangan untuk pengembangan pangan rumah tangga yang merupakan salah satu alternatif untuk mewujudkan kemandirian pangan dan meningkatkan penghasilan rumah tangga. Oleh karena itu, konsep ini mulai diterapkan di berbagai kota di Indonesia. Sadar bahwa peran perguruan tinggi adalah memberikan pencerahan kepada masyarakat akan hal positif, sehingga pengabdian ini akan ditujukan kepada masyarakat yang tinggal di wilayah perkotaan dan mempunyai lahan belum termanfaatkan secara optimal sebagai kawasan pangan lestari. Untuk menunjang keberhasilan program ini, diperlukan langkah-langkah kegiatan yaitu sosialisasi tentang konsep kawasan pangan lestari dengan memberikan pelatihan cara menanam komoditas penunjang konsep kawasan pangan lestari seperti bagaimana menyemai, menanam, merawat dan memanen tanaman kebutuhan rumah tangga. Produk-produk yang dipilih yaitu tanaman aneka lombok, aneka terong, aneka sayur dikarenakan antusiame dari kelompok PKK di Desa Dermo Kecamatan Bangil Kabupaten Pasuruan. Kegiatan sosialisasi ini dapat menggugah kesadaran masyarakat agar lebih peduli dengan lahan pekarangan rumahnya.
\end{abstract}

Kata Kunci : konsep kawasan pangan lestari, lahan, menyemai, menanam, merawat dan memanen

\begin{abstract}
The concept of a sustainable food areas is the concept of using land for household food development which is one alternative to realize food independence and increase household income. Therefore, this concept began to be applied in various cities in Indonesia. Realizing that the role of the institution is to give enlightenment to the public about positive things, so this dedication will be aimed at people who live in urban areas and have land that has not been optimally utilized as a sustainable food area. To support the success of this program, activity steps are needed, namely socialization the concept of sustainable food areas by providing training on how to plant commodities to support the concept of sustainable food areas such as how to sow, plant, care for and harvest crops for household needs. The selected products are lombok, eggplant, vegetables because of the enthusiasm of the PKK group in Dermo Village, Bangil District, Pasuruan Regency. This socialization can arouse public awareness to be more concerned with their home yards.
\end{abstract}

Keyword : the concept of sustainable food areas, land, sowing, planting, caring and harvesting 


\section{PENDAHULUAN}

\subsection{Latar Belakang}

Pembangunan ketahanan pangan saat ini dihadapkan pada permasalahan pokok, dimana pertumbuhan permintaan pangan lebih cepat dari pertumbuhan produksi pangan. Secara nasional, cepatnya pertumbuhan permintaan pangan baik dari sisi jumlah, mutu dan keragamannya disebabkan oleh beberapa faktor diantaranya adalah pertumbuhan penduduk, pertumbuhan industri, daya beli masyarakat serta perubahan preferensi konsumen. Disisi lain, kapasitas produksi pangan nasional terkendala oleh kompetensi dalam penggunaan lahan, perubahan iklim ekstrim, fenomena degradasi sumber daya alam dan lingkungan, dan terbatasnya dukungan infrastruktur pertanian [1].

Ketersediaan pangan dalam jumlah yang cukup sepanjang waktu merupakan keniscayaan yang tidak terbantahkan. Hal ini menjadi prioritas pembangunan pertanian nasional dari waktu ke waktu. Harapannya, setiap rumah tangga mengoptimalisasi sumberdaya yang dimiliki, termasuk pekarangan, dalam menyediakan pangan bagi keluarga [2].

Prinsip dasar KRPL adalah pemanfaatan pekarangan yang ramah lingkungan dan dirancang untuk ketahanan dan kemandirian pangan, diversifikasi pangan berbasis sumber daya lokal, konservasi sumberdaya genetik pangan (tanaman, ternak, ikan), dan menjaga kelestariannya melalui kebun bibit desa, serta peningkatan pendapatan dan kesejahteraan masyarakat.

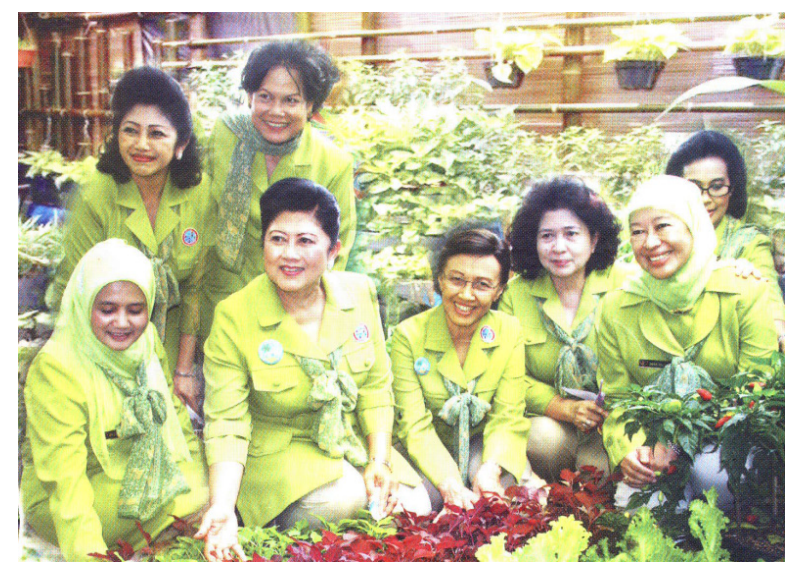

Gambar 1. Salah Satu Kawasan Pangan Lestari yang Sudah Berhasil
Optimalisasi potensi lahan pekarangan dapat menopang kehidupan sosial ekonomi masyarakat melalui program yang terencana dalam program pekarangan terpadu. Program pemanfaatan lahan pekarangan baru secara eksplisit dimasukkan menjadi bagian dalam proyek pengembangan diversifikasi pangan dan gizi. Kegiatan pemanfaatan lahan pekarangan dilaksanakan dengan memanfaatkan persediaan bahan makanan setempat dan mendukung perbaikan gizi masyarakat [3].

Kelompok Kerja Citra Agro Lestari merupakan kelompok kepedulian ibu-ibu PKK Desa Dermo Kecamatan Bangil Kabupaten Pasuruan. sudah melakukan kegiatan pemanfaatan pekarangan rumah. Tetapi kegiatan tersebut masih dilakukan secara sederhana dan tidak dilakukan dalam rangka untuk meningkatkan kesejahteraan warga. Oleh karena itu perlu dilakukan sosialisasi terhadap kegiatan tersebut agar lebih masif dan berdampak ekonomis.

Keinginan untuk mendapatkan manfaat yang lebih besar lagi pada kegiatan memanfaatkan lahan perkarangan rumah, mendorong anggota kelompok Kerja Citra Agro Lestari ingin membuat kegiatan ini tidak hanya melestarikan tetapi juga dapat berdampak ekonomis sehingga dapat meningkatkan kesejahteraan masyarakat.

\subsection{Masalah pada Mitra}

Dalam mewujudkan kawasan pangan lestari dengan cara memanfaatkan lahan pekarangan rumah, Kelompok Kerja Citra Agro Lestari ini mengalami beberapa kendala diantaranya adalah kurangnya pengetahuan tentang bagaimana cara mendesain konsep kawasan rumah pangan lestari yang indah dan asri, bagaimana cara memanfaatkan teknologi untuk mendukung konsep kawasan rumah pangan lestari serta bagaimana cara menghasilkan tanaman yang bermutu secara tepat.

Berdasarkan survey awal, hasil analisis terhadap permasalahan mitra dapat dirangkum pada Tabel 1. 
Tabel 1. Analisa Kondisi Mitra

\begin{tabular}{|c|c|}
\hline Aspek & Kelompok Citra Agro Lestari \\
\hline Keunggulan & $\begin{array}{l}\text { - Memiliki anggota yang } \\
\text { mempunyai semangat tinggi } \\
\text { untuk membudidayakan } \\
\text { tanaman } \\
\text { - Mempunyai keinginan untuk } \\
\text { meningkatkan kesejahteraan } \\
\text { melalui kegiatan } \\
\text { mengembangakan kawasan } \\
\text { rumah pangan lestari. }\end{array}$ \\
\hline Masalah & 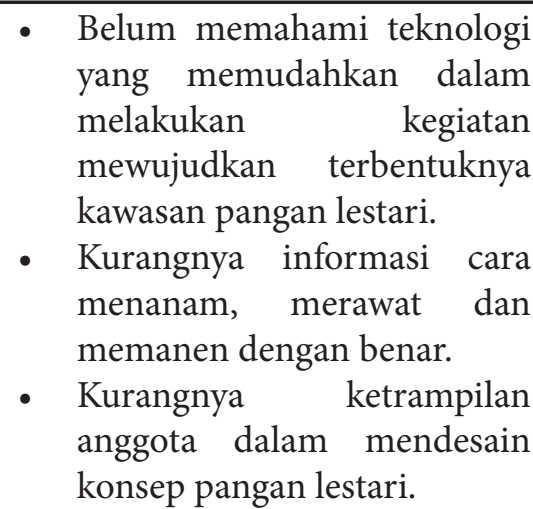 \\
\hline
\end{tabular}

\section{TARGET DAN LUARAN}

2.1 Solusi yang Ditawarkan

Berdasarkan analisis masalah pada kelompok Kerja Citra Agro Lestari di Desa Dermo Kecamatan Bangil Kabupaten Pasuruan maka sangat perlu untuk di bekali tentang :

1. Bagaimana cara menerapkan konsep kawasan pangan lestari yang indah dan asri;

2. Bagaimana cara menanam dan merawat serta memanen produk dari kawasan pangan lestari;

3. Bagaimana cara meningkatkan kesejahteraan masyarakat.

\subsection{Target Luaran}

Target luaran dari kegiatan ini adalah sebagai berikut :

1. Panduan berupa buku yang berisi tentang tata cara membuat konsep kawasan pangan lestari.

2. Ketrampilan anggota kelompok meningkat dalam hal menanam, merawat dan memanen hasil tanaman.

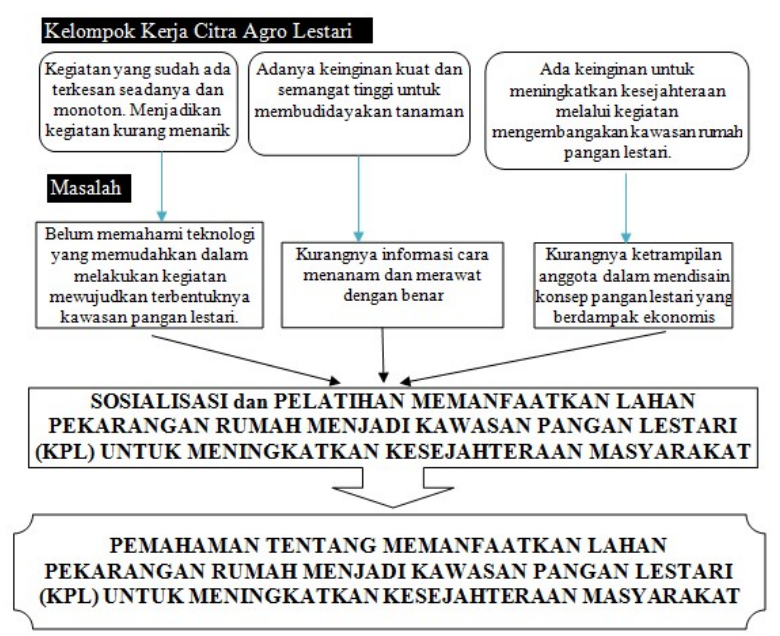

Gambar 2. Diagram Alir Target Luaran Sosialisasi

3. Anggota kelompok ( ibu-ibu) mempunyai penghasilan sendiri sehingga mampu membantu ekonomi keluarga.

Dengan demikian kegiatan ini akan berdampak positif terhadap lingkungan hidup, juga kegiatan ekonomi masyarakat (ecopreneurship).

\section{METODE PELAKSANAAN}

\subsection{Persiapan}

Dalam pelaksanaan kegiatan ini, metodologi yang digunakan seperti pada Gambar 3. Terdapat dua proses yaitu studi teknis dan analisis.

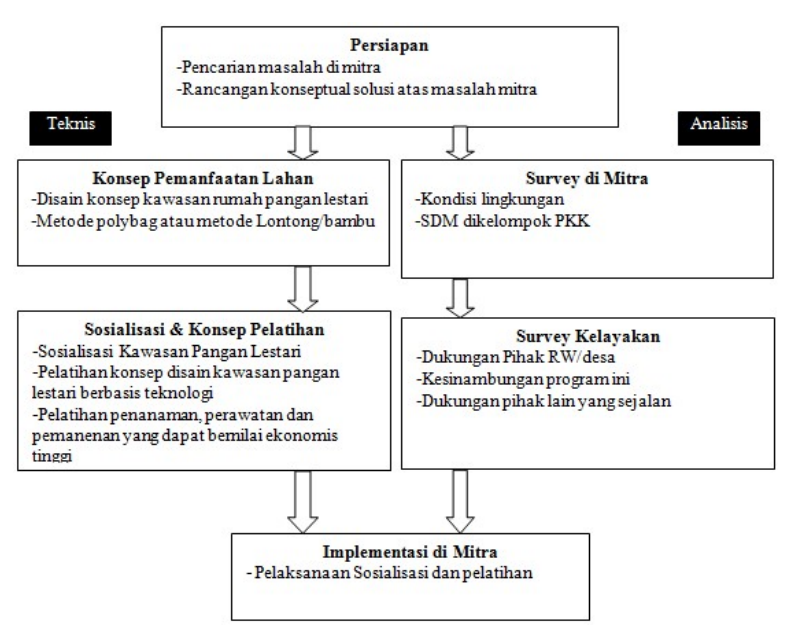

Gambar 3. Diagram Alir Metode Pelaksanaan 
Pada tahap ini dilakukan penggalian masalah terhadap mitra yaitu di Kelompok Kerja Citra Agro Lestari. Setelah tahap ini telah dilalui dan telah ditemukan masalah, selanjutnya dibuat rancangan konseptual solusi untuk masalah tersebut.

\subsection{Survey Kelayakan}

Pada tahap ini dilakukan survey kelompok PKK untuk menganalisa masalah lebih detail. Karena itu diperlukan data-data seperti apakah ada dukungan dari pihak RT, RW bahkan Kepala Desa dan apakah nantinya program ini dapat berkelanjutan, karena kegiatan ini akan diselaraskan dengan agenda dinas pertanian.

\subsection{Implementasi}

Setelah melakukan survey kelompok PKK, selanjutnya melaksanakan kegiatan sosialisasi dan pelatihan konsep kawasan rumah pangan lestari dengan memanfaatkan lahan yang tidak digunakan menjadi lahan produktif. Tujuannya adalah agar solusi yang ditawarkan segera diterapkan dan harapannya masyarakat dapat :

1. Mempunyai keseragaman pemahaman tentang konsep kawasan rumah pangan lestari;

2. Mempunyai kemampuan menerapkan teknologi tepat guna dalam mewujudkan kawasan rumah pangan lestari;

3. Mempunyai ketrampilan didalam menanam, merawat dan memanen produk sayuran dan lain-lain sehingga menjadi produk unggulan yang mempunyai nilai ekonomis tinggi;

4. Setiap anggota kelompok (ibu-ibu) mempunyai semangat dalam bisnis berbasis ecopreneurship sehingga mempunyai penghasilan sendiri dalam rangka membantu ekonomi keluarga.

\subsection{Sosialisasi dan Pelatihan}

Kegiatan ini disusun dalam beberapa tahapan yaitu sebagaimana tercantum pada Tabel 2.
Tabel 2. Rencana Sosialisasi dan Pelatihan

\begin{tabular}{|c|c|c|c|}
\hline $\begin{array}{l}\text { Perte- } \\
\text { muan }\end{array}$ & Materi & Metode & Target \\
\hline 1 & $\begin{array}{l}\text { Pentingnya } \\
\text { Kawasan rumah } \\
\text { pangan lestari }\end{array}$ & Ceramah & $\begin{array}{l}\text { Peserta me- } \\
\text { mahami apa } \\
\text { itu kawasan } \\
\text { rumah pan- } \\
\text { gan lestari }\end{array}$ \\
\hline 2 & $\begin{array}{l}\text { Peran teknologi } \\
\text { dalam menun- } \\
\text { jang penerapan } \\
\text { konsep kawasan } \\
\text { rumah pangan } \\
\text { lestari }\end{array}$ & Ceramah & $\begin{array}{l}\text { Peserta } \\
\text { mema- } \\
\text { hami Peran } \\
\text { teknologi } \\
\text { dalam } \\
\text { menunjang } \\
\text { penerapan } \\
\text { konsep } \\
\text { kawasan ru- } \\
\text { mah pangan } \\
\text { lestari } \\
\end{array}$ \\
\hline 3 & $\begin{array}{l}\text { Potensi pasar } \\
\text { hasil dari } \\
\text { kawasan rumah } \\
\text { pangan lestari }\end{array}$ & Ceramah & $\begin{array}{l}\text { Peserta } \\
\text { menjadi tahu } \\
\text { potensi pasar } \\
\text { hasil dari } \\
\text { kawasan ru- } \\
\text { mah pangan } \\
\text { lestaridan } \\
\text { kendalanya } \\
\text { dalam me- } \\
\text { masarkannya }\end{array}$ \\
\hline 4 & $\begin{array}{l}\text { Cara menanam, } \\
\text { merawat dan } \\
\text { memanen }\end{array}$ & $\begin{array}{l}\text { Ceramah } \\
\text { dan Prak- } \\
\text { tek }\end{array}$ & $\begin{array}{l}\text { Peserta } \\
\text { mampu } \\
\text { menanam, } \\
\text { merawat dan } \\
\text { memanen } \\
\end{array}$ \\
\hline 5 & $\begin{array}{l}\text { Step by step } \\
\text { menggapai } \\
\text { kesuksesan } \\
\text { bersama }\end{array}$ & $\begin{array}{l}\text { Ceramah } \\
\text { dan Prak- } \\
\text { tek }\end{array}$ & $\begin{array}{l}\text { Peserta } \\
\text { termotivasi } \\
\text { untuk terjun } \\
\text { menjadi } \\
\text { pebisnis }\end{array}$ \\
\hline
\end{tabular}

\section{HASIL YANG DICAPAI}

\subsection{Survey}

Survey kami lakukan sebelum melakukan program pengabdian kepada masyarakat ini. Kami menganalisa masalah secara detail. Kami mendapatkan data-data dukungan dari pihak RT, RW, dan Kepala Desa Dermo, Kecamatan Bangil, Kabupaten Pasuruan. Program dapat terlaksana dan diselaraskan dengan agenda dinas pertanian. 


\subsection{Pelaksanaan}

Sebelum pelaksanaan kegiatan, tim pengabdian masyarakat melakukan briefing dengan trainer yang ahli pada bidang ini beserta perangkat Desa Dermo. Saat pelaksanaan sosialisasi dan pelatihan konsep kawasan rumah pangan lestari dengan memanfaatkan lahan yang tidak digunakan menjadi lahan produktif, diberikan banyak pemahaman mengenai cara efektif menyemai, menanam, merawat dan memanen tanaman kebutuhan rumah tangga. Sosialisasi dilakukan untuk memudahkan pengetahuan awal bagi PKK Citra Agro Lestari kemudian dilakukan pelatihan mengenai pemanfaatan lahan untuk mengimplimentasikan konsep kawasan pangan lestari, serta dilakukan pembagian bibit aneka lombok, aneka terong, dan aneka sayur lainnya untuk menunjang keberhasilan dan keberlanjutan program ini.

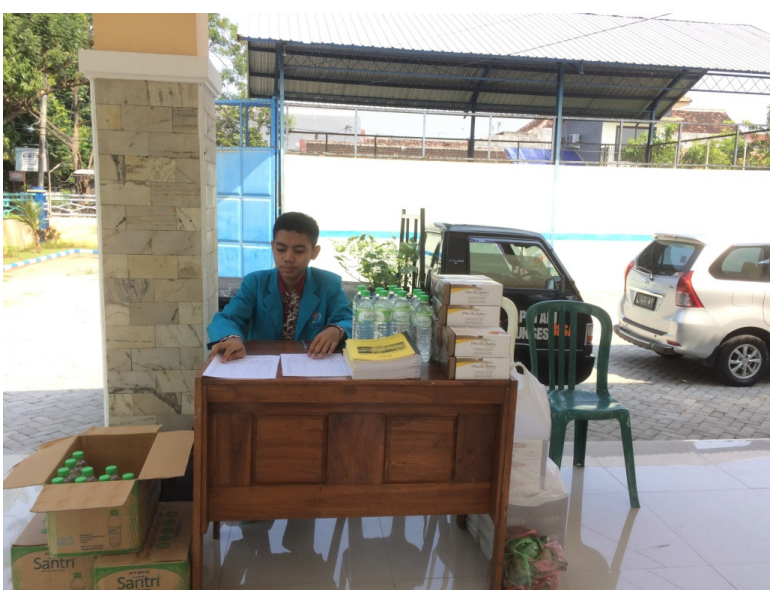

Gambar 4. Pendaftaran

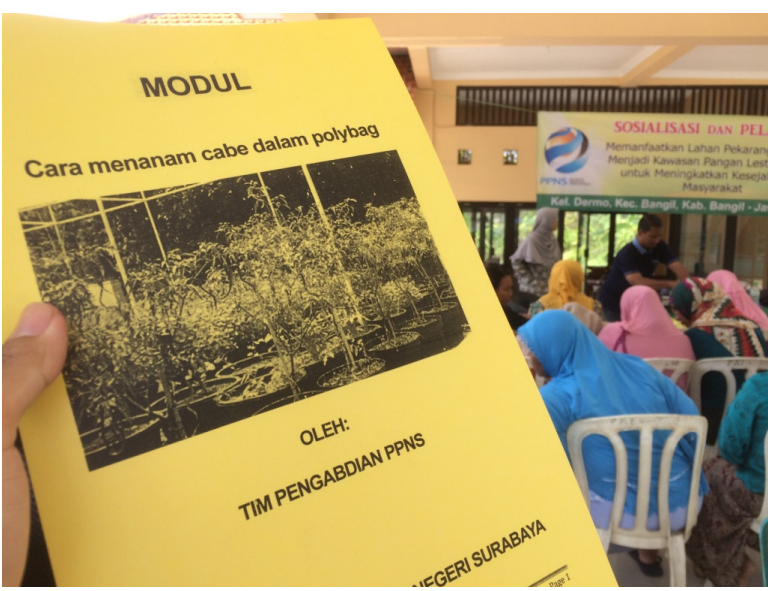

Gambar 5. Modul atau Buku Panduan Penunjang Konsep Kawasan Pangan Lestari

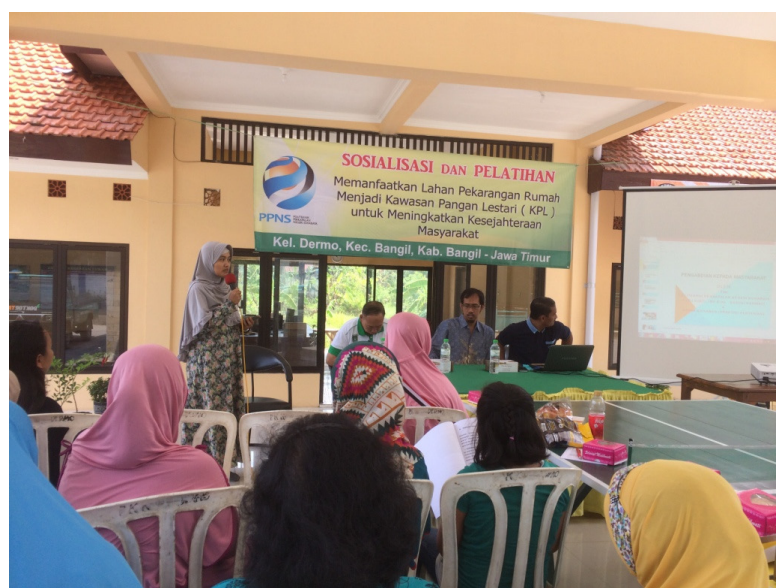

Gambar 6. Sosialisasi Konsep Kawasan Pangan Lestari

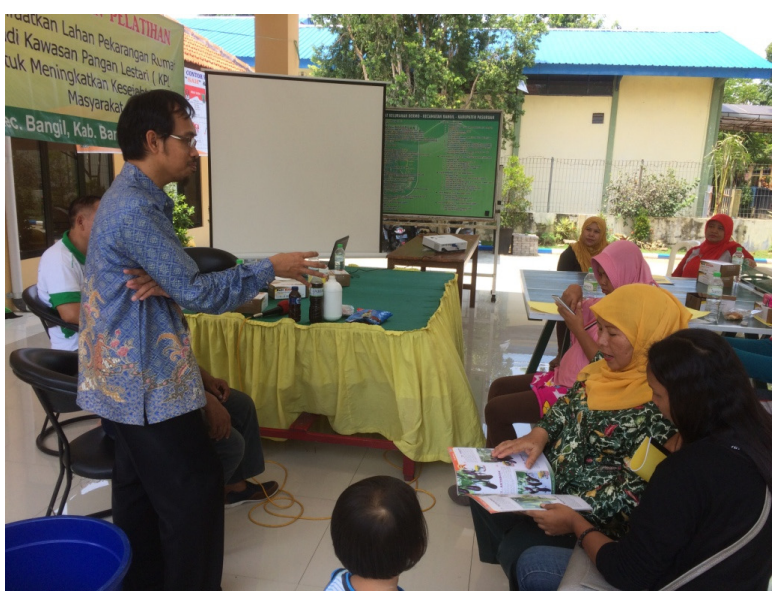

Gambar 7. Sosialisasi Cara Efektif Menyemai, Menanam, Merawat dan Memanen Tanaman Kebutuhan Rumah Tangga oleh Trainer

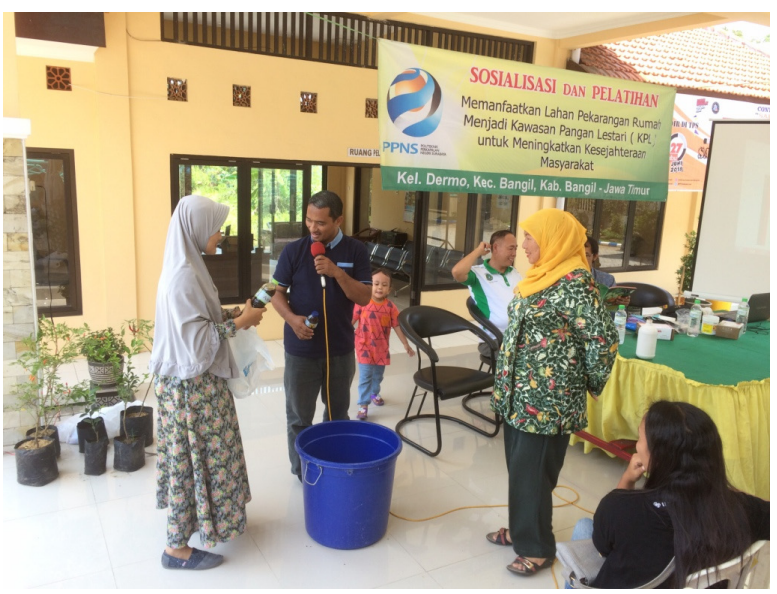

Gambar 8. Pelatihan Pemanfaatan Lahan menuju Kawasan Pangan Lestari oleh Tim dan Trainer 


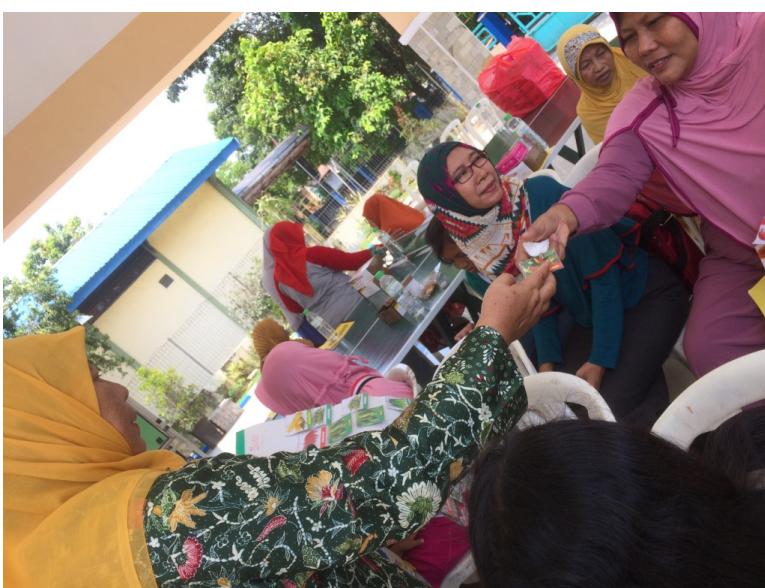

Gambar 9. Pembagian Bibit Aneka Tanaman

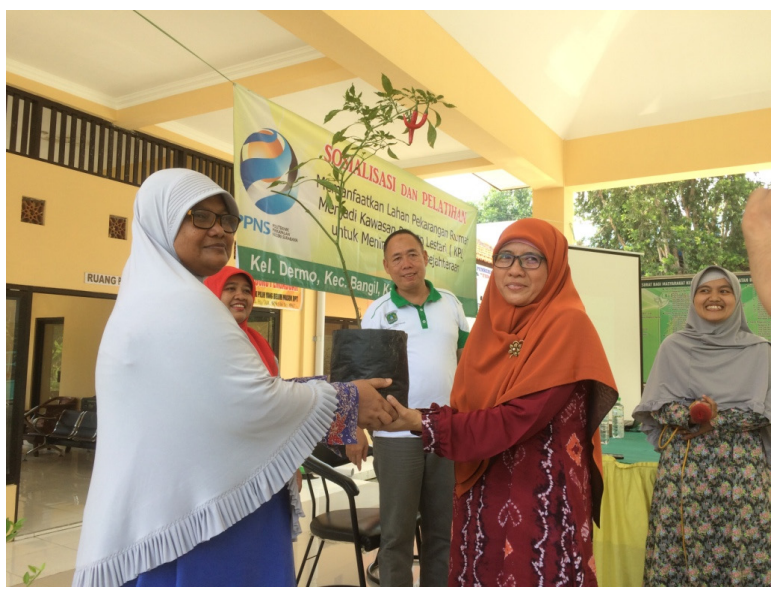

Gambar 10. Serah Terima Tanaman Hasil Sosialisasi dan Pelatihan

\subsection{Hasil yang Dicapai}

Dihasilkannya kawasan pangan lestari di Desa Dermo Kecamatan Bangil Kabupaten Pasuruan yang mengedepankan prinsip kesejahteraan masyarakat dan kemandirian dalam produksi kebutuhan pangan rumah tangga dengan tingkat keberhasilan dan kesesuaian target dengan rencana kegiatan $100 \%$. Selain itu, kegiatan pemanfaatan lahan pekarangan rumah menjadi Kawasan Pangan Lestari (KPL) dirintis dengan cara menjalin mitra dengan kelompok kerja Argo Citra Lestari yang menghasilkan panduan berupa buku yang berisi tentang tata cara membuat konsep kawasan pangan lestari, meningkatkan ketrampilan anggota kelompok dalam hal menanam, merawat dan memanen hasil tanaman, serta memberikan jalan alternatif anggota kelompok (ibu-ibu) untuk dapat berpenghasilan sendiri sehingga mampu menunjang ekonomi keluarga.

Proses pemantauan kegiatan pasca sosialisasi dan pelatihan pemanfaatan lahan pekarangan rumah menjadi Kawasan Pangan Lestari (KPL) dilakukan secara komunikasi dalam suatu media sosial dan dilakukan secara langsung ke lokasi Desa Dermo Kecamatan Bangil Kabupaten Pasuruan. Hasilnya, pekarangan rumah kelompok PKK Argo Citra Lestari yang menerapkembangkan kegiatan ini dapat dimaksimalkan potensinya sebagai lahan untuk penanaman tanaman pangan rumah tangga dan telah membuahkan hasil yang bermanfaat. Hal ini menunjukkan bahwa kegiatan ini telah terlaksana dan dapat mencapai target, serta mampu menjadi jembatan peningkat kesejahteraan masyarakat.

\section{KESIMPULAN DAN SARAN}

\subsection{Kesimpulan}

Berikut merupakan beberapa kesimpulan yang dapat ditarik mengenai kegiatan sosialisasi dan pelatihan pemanfaatan lahan pekarangan rumah menjadi Kawasan Pangan Lestari (KPL) diantaranya yaitu sebagai berikut :

1. Untuk menyeragamkan pemahaman tentang konsep kawasan rumah pangan lestari terhadap masyarakat dapat dilakukan dengan cara sosialisasi dan pelatihan, serta pendampingan yang berkelanjutan;

2. Penerapan teknologi tepat guna mengenai kawasan pangan lestari yang dilakukan di Desa Dermo Kecamatan Bangil Kabupaten Pasuruan telah terealisasi dan dapat mewujudkan kawasan rumah pangan lestari;

3. Kelompok PKK Argo Citra Lestari telah memiliki ketrampilan didalam menanam, merawat, dan memanen produk tanaman pangan rumah tangga dan siap untuk terjun dalan dunia bisnis yang berbasis ecopreneurship.

\subsection{Saran}

Berikut merupakan beberapa saran yang dapat diberikan setelah kegiatan pengabdian masyarakat ini diantaranya yaitu :

1. Sebaiknya pelatihan dilakukan secara rutin untuk memaksimalkan penyeragaman konsep 
penanaman kawasan pangan lestari;

2. Sebaiknya trainer dalam setiap kegiatan merupakan trainer yang telah ahli dalam bidangnya serta dapat memotivasi sasaran untuk lebih menerapkembangkan ilmu teknologi yang telah disosialisaikan;

3. Sebaiknya sasaran kegiatan ini dapat diperluas sehingga membantu pemerintah Indonesia dalam menumbuhkan produktivitas negara di bidang pangan.

\section{DAFTAR PUSTAKA}

[1] Pengembangan Kawasan Rumah Pangan Lestari, Kementrian Pertanian, 2013.

[2] Prospect of The Model of Sustainable Food House Region and Its Replication, Saptono, Sumarsih dan Supeno Priyanto, Pusat Sosial Ekonomi dan Kebijakan Pertanian, 2014.

[3] KAWASAN RUMAH PANGAN LESTARI (KRPL): Sebagai Solusi Pemantapan Ketahanan Pangan1, Handewi Purwati Saliem, Kongres Ilmu Pengetahuan Nasional (KIPNAS), di Jakarta tanggal 8-10 November 2011. 
Binti Mualifatul Rosydah, Rini Indarti, M. Basuki Rahmat, Isa Rachman, Purwidi Asri, Mey Rohma Dhani, Achmad Ainnurzein, Lutfi Wicaksono, Bella Naziel Iqmalia

Halaman ini sengaja dikosogkan 